From the methanogenic bacterium $M$. thermoautotrophicum it is possible to isolate a yellow, low molecular weight nickel-containing compound with an absorption maximum at $430 \mathrm{~nm}$, hence named factor $F_{430}$ (ref. 7). This factor has been found in every methanogenic bacterium so far examined ${ }^{8}$. The extinction coefficient at $430 \mathrm{~nm}$ is high, $\sim 23 \times 10^{3}$ per $\mathrm{cm}$ per mol Ni. The exact structure of this pigment has not yet been elucidated but there is evidence from the biosynthetic incorporation of $\delta$-amino laevulinic acid that $\mathrm{F}_{430}$ is a nickel tetrapyrrole ${ }^{14}$. Chemical degradation products of $F_{430}$ have appreciable absorption in the region $500-600 \mathrm{~nm}$ and react with cyanide. It has been suggested that the spectrum resembles that of vitamin $B_{12}$ with, presumably, the implication that the nickel species is related to nirrin, the nickel analogue of corrin' ${ }^{1}$. There is evidence of a mechanistic kind that the carbon monoxide oxidation in acetogenic bacteria may also involve a prosthetic group similar in structure in vitamin $B_{12}$ but with nickel in place of cobalt $^{15}$. There is a very recent report that the co-enzyme of the purified methyl reductase of $M$. thermoautotrophicum is $\mathrm{F}_{430}$, with a stochiometry of $1 \mathrm{~mol}$ of nickel per mol of $F_{430}$ and 2 mol of $F_{430}$ per mol of

\title{
Remote operation of telescopes
}

\section{from Michael Penston}

BRITISH astronomers have recently moved to the fore in several branches of optical astronomy, thanks largely to the building of new telescopes in favourable sites abroad - in particular the AngloAustralian Telescope at Coonabarabran, New South Wales, and the UK Infrared Telescope (UKIRT) on Mauna Kea in Hawaii. Access to the telescopes has, not surprisingly, so far depended on the opportunities provided by air travel. Now, astronomers have begun discussing whether modern communications technology offers an alternative way of working. Early in June experts in communcations and computer technology came together with astronomers and builders of astronomical instruments at the Royal Greenwich Observatory (RGO) to discuss the feasibility of remote operation of telescopes*.

Remote operations of telescopes is possible and, indeed, has already been carried out in an experimental way by Kitt Peak National Observatory and UKIRT. The Kitt Peak $4 \mathrm{~m}$ and $2.1 \mathrm{~m}$ telescopes

*The two-day workshop on 'Remote operation of telescopes' was held at Herstmonceaus Castle, hume of the Royal Greenuich Observatory. Participants included representatives from UKIRT, Kitt Pcak National Observatory, the European Southern Observatory and the Furopean Space Agency as well a British astronomers and esperss in computer nelworking. methyl reductase ${ }^{16}$.

Thus it is now clear that there are at least two new classes of nickel-containing enzymes: the nickel-containing hydrogenases and those with a nickel tetrapyrrole-related co-factor. Much work on their structural elucidation needs to be carried through.

1. Thauer, R.K., Diekert, G. \& Schonheit, P. Trends biochem. Sci. 11, 304 (1980)

2. Dixon, N.E., Gazzola, C., Blakeley, R.L. \& Zerner, B. J. Am. chem. Soc. 97, 413 (1975).

3. Albracht, S.P.J., Graf, E.G. \& Thauer, R.K. FEBS Lett. 140, 311 (1982).

4. Legall, J. et al. Biochim. biophys. Res. Commun. 106,610 (1982).

5. Cammack, R., Patil, D., Afluire, R. \& Htchikian, E.C FEBS Lett. 142, 289 (1982).

6. Drake, H.L., Hu, S.L. \& Wood, H.G. J. biol. Chem 255, 7174 (1980).

7. Diekert, G., Klee, B. \& Thauer, R.K. Arch. Microbiol. 124, 103 (1980).

8. Whitman, W.B. \& Wolfe, R.S. Biochem. biophys. Res. Commun. 92, $1196(1980)$.

9. Brooks, R.R., Morrison, R.S., Reeves, R.D., Dudley, T.R. \& Akman, Y. Proc. R. Soc. 203, 387 (1979).

10. Bartha, R. \& Ordal, E.J. J. Bact. 89, 1015 (1975).

11. Lancaster, J.R. Jr FEBS Lett. 115, 285 (1980).

12. Bossu, F.P. \& Margerum, D.W. Inorg. Chem. 16 1210 (1977).

13. Diekert, G.B. \& Thauer, R.K. FEMS Microbiol. Lett. 7, 187 (1980).

14. Diekert, G., Jaenchen, R. \& Thauer, R.K. FEBS Lett. 199. 118 (1980).

15. Diekert, G.B. \& Thauer, R.K. J. Bact. 134, 597 (1978).

16. Ellefson, W.L., Whitman, W.B. \& Wolfe, K.S. Proc natn. Acad. Sci. U.S.A. 79, 3707 (1982). telescope mirror than the traditional test of 'whether the dome rail is wet' needs to be developed. A more professional approach would even benefit conventional observing with the observer present.

The financial benefits of remote observing are obvious, given rising air fares and falling communications costs. Advantages in flexibility might also be provided - the difficulties of scheduling simultaneous observations on different telescope and/or satellites might, for example, be eased. When some particularly demanding meteorological requirement is expected to be met for only a short time (for example, conditions dry enough to use an IR telescope in the $350 \mu \mathrm{m}$ 'window') it would be easier to put a different observer on the telescope if he did not have to travel so far to exploit this short period. Efficiency would also be improved as astronomers would spend less time travelling and recovering from jet-lag.

There are individual problems in communicating from different sites as reports by Paul Bryant (Rutherford and Appleton Laboratories) and Peter Kirstein (University College London) showed a somewhat anarchic situation in the communications field. There are differences in computer-to-computer communication protocols, in line tariffs and in regulations from country to country so that the best solution at one observatory might not apply at another. Obviously, however, common requirements exist and common solutions and standards are highly desirable as participants, looking ahead, foresaw a network for remote operation of telescopes linking Australia, Hawaii, Chile, continental United States, the Canary Islands and Europe. One solution to the present problem was to separate the difficulties of communication and control, defining interfaces between these segments only. Thus cheap entry to the field could be obtained with use of dial-up telephone lines, as at present, and when wide band lines or public packet switching networks become cheaper it would be possible to change to them with minimum distruption. The eventual use of wide-band 50 kbit lines was foreseen since that would allow nearreal-time transmission of astronomical data from the telescope to the site of remote operations. In the meantime it seems most practical to progress using two to three dedicated telephone lines.

At the end of the meeting Alec Boksenberg, Director of the RGO, undertook to have remote operation from Herstmonceux of the $2.5 \mathrm{~m}$ Isaac Newton and $1.0 \mathrm{~m}$ telescopes on La Palma working by the end of next year. Obviously at this pace, the sky is the limit in the remote operations field. rate to be satisfactory. On the other hand, present astronomical practises regarding weather monitoring and protection of the instruments from damage were not so easily compatible with remote operation. A better ways of determining whether the humidity is high enough to hazard the
Michael Penston is at the Royal Greenwich Observatory, Herstmonceaux Castle, Hailsham, East Sussex BN27 IRP. 